\title{
O caso Pedro Henrique: políticas públicas para adolescentes em conflito com a lei (Santa Catarina, década de 1990) ${ }^{1}$
}

\section{The Pedro Henrique case: public policies for adolescents in conflict with the law (Santa Catarina, 1990s)}

\author{
Silvia Maria Fávero Arend* \\ https://orcid.org/0000-0002-3262-5596 \\ Otoniel Rodrigues Silva* \\ https://orcid.org/0000-0002-3729-196X
}

\begin{abstract}
Resumo
O artigo objetiva analisar como os preceitos do Estatuto da Criança e do Adolescente em relação aos adolescentes em conflito com a lei foram recepcionados pelos gestores públicos do Estado de Santa Catarina na década de 1990. A partir de fontes produzidas pelo Poder Judiciário estadual e pelo Ministério Público de Santa Catarina, procurou-se identificar as principais características vigentes nestas ações. As fontes foram analisadas sob a ótica da História da Infância e Juventude. Dentre estas características, destacamse os problemas enfrentados no processo de municipalização das políticas públicas e as violações de direitos humanos ocorridas no principal centro de internação do estado para adolescentes em conflito com a lei, localizado na região da Grande Florianópolis. A partir da intervenção dos representantes do Ministério Público de Santa Catarina em 1995, estas políticas públicas tomaram novo rumo, quando foram alinhadas paulatinamente ao prescrito na lei.
\end{abstract}

Palavras-chave: Adolescentes em conflito com a lei. Estatuto da Criança e do Adolescente. Santa Catarina. Políticas Públicas.

\begin{abstract}
The article aims to analyze how the precepts of the Statute on Children and Adolescents regarding adolescents in conflict with the law were received by
\end{abstract}

\footnotetext{
${ }^{1}$ Neste artigo optamos por utilizar o termo "adolescente em conflito com a lei" em contraposição a semântica pejorativa do termo "adolescente infrator". Esta terminologia foi inserida no contexto sociojurídico nacional a partir do advento do Estatuto da Criança e do Adolescente em 1990. Todavia, o termo "adolescente infrator" será mantido quando da reprodução das fontes

"Doutora em História pela Universidade Federal do Rio Grande do Sul (UFRGS). Professora do curso de Graduação em História e dos Programas de Pós-graduação em História e em Educação da Universidade do Estado de Santa Catarina (UDESC). E-mail: silvia.arend@udesc.br

** Mestre em Educação pela Universidade do Sul de Santa Catarina (Unisul). Professor de Pedagogia no Instituto Federal do Paraná (IFPR). Doutorando do Programa de Pós-graduação em Educação da Universidade do Estado de Santa Catarina (UDESC). E-mail: otoniel.silva@ifpr.edu.br
} 
public managers in the state of Santa Catarina in the 1990s. Starting with sources produced by the State Judiciary and the Public Ministry of Santa Catarina, an attempt was made in order to identify the main characteristics in force in these actions. The sources were analyzed from the perspective of the History of Childhood and Youth. Among these characteristics, the problems faced in the process of municipalization of public policies and human rights violations that occurred in the main detention center for adolescents in conflict with state law, located in the Metropolitan Region of Florianópolis, stand out. From the intervention of representatives of the Public Ministry of Santa Catarina in 1995, these public policies took a new direction, as they were gradually aligned with what is prescribed by law.

Keywords: Adolescents in conflict with the law. Child and Adolescent Statute. Santa Catarina. Public policies.

\section{Introdução}

Em abril de 1997, passados quase sete anos desde a promulgação do Estatuto da Criança e do Adolescente e cinco anos da extinção da Fundação Catarinense do Bem-Estar do Menor (Fucabem), Pedro Henrique, ${ }^{2}$ à época com 12 anos, foi acusado da prática de ato infracional análogo a furto. Em decorrência de decisão judicial, o adolescente passou a cumprir medida socioeducativa de internação provisória de até 45 dias. Findada a internação provisória, o adolescente foi sentenciado com medida de internação permanente, que poderia durar até três anos. Após permanecer internado por mais de um ano, em junho de 1998, por se recusar a sair da quadra de esportes ao final de uma partida de futebol de salão, discutiu com colegas e com os monitores que faziam plantão naquele dia, além de se desentender com o pedagogo e com o psicólogo da instituição. Devido ao seu considerado "mau" comportamento, como sanção disciplinar, Pedro Henrique foi trancado em seu quarto. ${ }^{3}$ Minutos depois do recolhimento, um incêndio tomou conta de seu aposento. Logo que

\footnotetext{
${ }^{2}$ Por questões éticas e conforme o pactuado com o Poder Judiciário do Estado de Santa Catarina, para o acesso aos processos judiciais ora analisados, visando manter a incolumidade das pessoas direta ou indiretamente citadas nos processos judiciais e demais documentos utilizados como fontes desta investigação, as pessoas terão suas identidades preservadas por meio do uso de pseudônimos.

${ }^{3}$ Utiliza-se o termo 'quarto' conforme registrado nos autos. Contudo, a partir das fotografias anexadas ao processo jurídico, podemos afirmar que o espaço onde Pedro Henrique estava isolado era de fato uma cela. O 'quarto' possuía aproximadamente quatro metros quadrados, uma janela gradeada por barras de concreto e uma robusta porta de madeira maciça, com duas trancas e cadeados na parte externa.
} 
percebido o incêndio, os monitores abriram a porta e procuraram conter as chamas que se alastravam pelo quarto. Porém, não foi possível salvar a vida de Pedro Henrique, que faleceu antes da chegada do socorro médico.

Neste artigo, analisa-se o processo penal ${ }^{4}$ decorrente da morte do referido adolescente, e mais um Termo de Compromisso de Ajustamento de Conduta pactuado entre governo estado de Santa Catarina e o Ministério Público (MPSC), com vistas a solucionar problemas no Sistema de Atendimento ao Adolescente Infrator. ${ }^{5}$ A partir destas fontes jurídicas produzidas pelo Poder Judiciário estadual e pelo Ministério Público de Santa Catarina, objetiva-se compreender como o Estatuto da Criança e do Adolescente foi recepcionado pelos gestores públicos no estado, particularmente no âmbito de crianças ou adolescentes sob a acusação da prática de atos infracionais na década de 1990.

Em 27 de abril de 1992, por meio do Decreto nํ⒈653, o então governador do estado, Vilson Kleinübing, declarou extinta a Fundação Catarinense de Bem-Estar do Menor (Fucabem). Criada em 1975, durante a ditadura militar (1964-1985), a entidade funcionou como uma espécie de "subsidiária" estadual da Fundação Nacional do Bem-Estar do Menor (Funabem), órgão do governo federal responsável por formular políticas oficiais para a população infantojuvenil brasileira, especialmente para a acusada pelas autoridades governamentais de praticar atos infracionais.

A extinção da entidade, então responsável por dar "execução às sentenças da Justiça de Menores", ${ }^{6}$ pode ser compreendida como ressonância do processo de redemocratização do país, irrompido na década de 1980 . Neste período, entre outras conquistas sociais, por meio do Artigo no 227 da Constituição Federal de 1988, foi positivado no ordenamento jurídico brasileiro a Doutrina da Proteção Integral à Criança e ao Adolescente. Dessa forma, a sociedade brasileira lentamente começava a reconhecer crianças e adolescentes como sujeitos de direitos e como população prioritária no acesso às políticas públicas.

A partir da ascensão da Doutrina da Proteção Integral à Criança e ao Adolescente, no campo legal brasileiro, o país alinhou-se aos considerados avanços do direito infantojuvenil que emergia no cenário internacional. Desde

\footnotetext{
${ }^{4}$ Processo Penal número 0004164 [...] 1ํ Cartório Criminal da Comarca de São José (Santa Catarina). 0 processo penal acerca do caso de Pedro Henrique tramitou em segredo de Justiça. Sendo assim, sua identificação será realizada de forma parcial.

${ }^{5}$ O TAC é fruto do Inquérito Civil Público (ICP) 001/95, instaurado pelo MPSC, por meio da Portaria nº 809, de 2 de agosto de 1995.
}

${ }^{6}$ SANTA CATARINA, Lei nº 5.089, de 14 de maio de 1975. 
o ano de 1978 os representantes da Organização das Nações Unidas (ONU) debatiam a proposta de uma normativa internacional com vistas a ampliar o espectro de direitos para os menores de idade. ${ }^{7}$ Hebe Signorini Gonçalves sintetiza os princípios da referida doutrina pautada nos princípios jurídicos do protecionismo, provisão e protagonismo:

A doutrina da proteção integral compreende a criança como sujeito de direitos; defende a inclusão dos direitos de crianças e adolescentes nos códigos legislativos, e afirma ainda que esses segmentos são detentores privilegiados dos direitos de cidadania, o que implica a discriminação positiva da criança e do adolescente. $^{8}$

Em 1990, por meio do Estatuto da Criança e do Adolescente, ${ }^{9}$ os princípios da Doutrina da Proteção Integral à Criança e ao Adolescente foram incorporados à legislação nacional. Ao longo de 267 artigos, essa legislação instituiu um conjunto grande de direitos e deveres da população menor de 18 anos. O Estatuto da Criança e do Adolescente buscou romper com o discurso jurídico de cunho "menorista", vigente na área desde a instituição do Código de Menores de 1927, discurso que admitia a intervenção e a tutela estatal na vida de crianças e adolescentes, especialmente das que viviam em condição de pobreza, inclusive por meio da institucionalização. ${ }^{10}$

Ainda durante a tramitação do Estatuto da Criança e do Adolescente no Congresso Nacional, amplos setores da sociedade brasileira aglutinaram-se em apoio à aprovação da lei, com destaque para representantes do campo jurídico, político, acadêmico e dos movimentos sociais de defesa dos direitos da infância. De acordo com representantes destes segmentos sociais, o Estatuto da Criança e do Adolescente não se limitava a positivar direitos, mas buscava reverter a histórica condição de sujeição que se abatia sobre as infâncias pobres brasileiras. Tratava-se, portanto, de um ordenamento jurídico capaz de estabelecer uma ruptura na distinção oriunda do discurso jurídico que se difundiu no senso comum e aplicado aos filhos e filhas das elites e das camadas

\footnotetext{
${ }^{7}$ AREND, Silvia Maria Fávero. Direitos Humanos e Infância: construindo a Convenção sobre os Direitos da Criança (1978-1989), Tempo [online]. 2020, v. 26, n. 3 p. 605-623. Disponível em: <https://doi.org/10.1590/ TEM-1980-542X2020v260305>. Acesso em: jul/2021.

${ }^{8}$ GONÇALVES, Hebe Signorini. Medidas socioeducativas: avanços e retrocessos no trato do adolescente autor de ato infracional. In: ZAMORA, Maria Helena (Org.). Para além das grades: elementos para a transformação do sistema socioeducativo. Rio de Janeiro: PUC-Rio; São Paulo: Loyola, 2005. p. 35-61.

${ }^{9}$ BRASIL. Lei $n^{\circ} 8.069$, de 13 de julho de 1990.

${ }^{10}$ VERONESE, Josiane Rose Petry. Os direitos da criança e do adolescente. São Paulo. LTr, 1999.
} 
médias - chamados, em geral, de "crianças e adolescentes", - e aos(às) filhos(as) dos pobres - identificados(as) como "menores".

As primeiras duas legislações brasileiras para as infâncias, o Código de Menores de 1927 (Decreto nº 17.943-A, de 12 de outubro de 1927); e o Código de Menores de 1979 (Lei no 6.667, de 10 de outubro de 1979), utilizavam a categoria jurídica "menores". o pedagogo Roberto da Silva infere sobre os significados da referida categoria jurídica no que tange ao Código de Menores de 1979, que foi elaborado sob os auspícios da Associação Brasileira de Juízes de Menores. Segundo o autor:

A Doutrina da Situação Irregular, que substituiu a Doutrina do Direito do Menor ao ser aprovado o Código de Menores de 1979, é uma construção doutrinária oriunda do Instituto Interamericano del Niño, órgão da Organização dos Estados Americanos (OEA), do qual o Brasil participa, juntamente com os Estados Unidos, o Canadá e os demais países das Américas. Sua formulação teórica é atribuída ao jurista argentino Ubaldino Calvento e teve como maior propagador no Brasil o juiz de menores do Rio de Janeiro, Alyrio Cavallieri. A Associação Brasileira de Juízes de Menores incorporou tal conceito a partir do seu XIV Congresso, realizado no Chile em 1973, sob a justificativa de que se adequava à tradição legislativa brasileira só tomar conhecimento da problemática da criança a partir do momento em que se configurasse que ela se encontrava em situação irregular na família. [...] Sob essa categoria, o Código de Menores de 1979 passou a designar as crianças privadas das condições essenciais de sobrevivência, mesmo que eventuais; as vítimas de maus-tratos e castigos imoderados; as que se encontrassem em perigo moral, entendidas como as que viviam em ambientes contrários aos bons costumes e as vítimas de exploração por parte de terceiros; as privadas de representação legal pela ausência dos pais, mesmo que eventual; as que apresentassem desvios de conduta e as autoras de atos infracionais. ${ }^{11}$

Diferente do Código de Menores de 1979, o Estatuto da Criança e do Adolescente assegurou um conjunto grande de direitos a todas as crianças e adolescentes brasileiras. A partir da vigência do Estatuto da Criança e do Adolescente, por não estarem em consonância com as prescrições do novo

\footnotetext{
${ }^{11}$ SILVA, Roberto da. A construção do direito à convivência familiar e comunitária no Brasil. In: SILVA, Enid Rocha Andrade da. (coord.). 0 direito à convivência familiar e comunitária: os abrigos para crianças e adolescentes no Brasil. Brasília: IPEA/CONANDA, 2004. p. 293. Grifo nosso.
} 
ordenamento jurídico, a Fucabem e outras instituições no estado de Santa Catarina que atuavam no âmbito dos chamados "problemas dos menores" foram extintas ou reestruturadas, como ocorreu em outras unidades da federação. Este processo de "reorganização" das instituições governamentais pode ser percebido como um marco que pôs fim a um determinado modo de governo desta população, ${ }^{12}$ ao mesmo tempo em que inaugurou outro.

A opção prioritária pela tipologia de fontes exploradas no presente estudo, o processo penal sobre o caso de Pedro Henrique e o Termo de Compromisso de Ajustamento de Conduta, se deve à possibilidade de identificar "vozes" nos documentos que enunciem discursos capazes de evidenciarem práticas e representações sociais ${ }^{13}$ acerca das concepções de Justiça de determinado período histórico. Os historiadores Pedro Cantisano e Mariana Armond Dias Paes apresentam importante reflexão sobre as fontes produzidas pelo campo do Direito. De acordo com os autores:

Ainda é bastante recorrente na historiografia a ideia de que "direito" é "lei", no sentido de normas escritas promulgadas por autoridades governamentais. No entanto, "direito" é um campo normativo muito mais amplo do que a legislação escrita. As normas, categorias e institutos jurídicos são produzidos em diversos locais, para além da lei propriamente dita. Os tribunais e os processos judiciais são locais de produção do direito, não de mera aplicação ou disputa. É um fato que, nos tribunais e nos processos judiciais, discutem-se e disputam-se diferentes concepções de justiça. Porém, nessas disputas, as normas, categorias e institutos jurídicos adquirem significados concretos. Em outras palavras, o direito também é produzido em disputas judiciais. ${ }^{14}$

Em relação aos autos, selecionou-se o referente a Pedro Henrique em virtude da representatividade do caso no contexto do estudo das políticas públicas implementadas em Santa Catarina no período da redemocratização. 0 processo jurídico, constituído por 297 páginas, além de fornecer informações sobre a vida pregressa de Pedro Henrique e de sua família, possibilita inferências sobre como as ações desenvolvidas no campo das políticas públicas e

\footnotetext{
${ }^{12}$ FOUCAULT, Michel. Segurança, território e população. São Paulo: Martins Fontes, 2008.

${ }^{13}$ MOSCOVICI, Serge. Representações sociais: investigações em psicologia social. Petrópolis, RJ: Vozes, 2007.

${ }^{14}$ CANTISANO, Pedro e DIAS PAES, Mariana Armond. Apresentação: Processos judiciais e escrita da história na América Latina. Varia História [online]. 2021, v. 37, n. 74, p. 355. Disponível em: <https://doi. org/10.1590/0104-87752021000200002>. Acesso em: jul/2021.
} 
dos órgãos estatais - Polícia, Ministério Público e Poder Judiciário - foram de fundamental importância na "trajetória" do adolescente..$^{15}$

Estas fontes possibilitam a análise das distintas versões apresentadas pelos agentes sociais envolvidos em cada caso, oportunizando ao trabalho historiográfico a compreensão das articulações dos vetores que constituíam aquela realidade social. ${ }^{16}$ Sobre a pesquisa em autos judiciais, cabe acentuar o que aponta Sidney Chalhoub:

É na análise de cada versão no contexto de cada processo, e na observação da repetição das relações entre as versões em diversos processos, que podemos desvendar significados e penetrar nas lutas e contradições sociais que se expressam e, na verdade, produzem-se nessas versões ou leituras. ${ }^{17}$

Tendo em vista esta perspectiva, o pesquisador é instigado a compreender o contexto de produção de cada peça que compõe os autos e o Termo de Compromisso de Ajustamento de Conduta, sendo necessário questionar: quem o produziu, a quem foi endereçado e com que propósito? Ademais, entende-se que o discurso do Direito não se translada mecanicamente do prescrito na letra da lei às práticas sociais. É importante lembrar que a positivação e a aplicação do discurso jurídico se encontram atravessados sobretudo pelo cenário político vigente à época e pela ação dos Operadores do Direito e de outros agentes sociais. ${ }^{18}$

\section{Fucabem: a pedra angular do Sistema de Atendimento ao Adolescente Infrator na ditadura militar}

As condições de atendimento ao "adolescente em conflito com a lei" que vigoraram no estado de Santa Catarina até a década 1990 têm suas raízes fincadas em processos sociopolíticos das décadas de 1960 e 1970. A distribuição espacial da população do estado em pequenas cidades, o predomínio de áreas rurais e uma dinâmica econômica em parte acentuada durante o chamado "milagre econômico" ocorrido durante a ditadura militar, contribuíam para

\footnotetext{
${ }^{15}$ BOURDIEU, Pierre. A ilusão bibliográfica. In: FERREIRA, Marieta de Moraes; AMADO, Janaina (org.). Usos e abusos da História Oral. Rio de Janeiro: Editora da FGV, 1996. p. 183-191.

${ }^{16}$ CHALHOUB, Sidney. Trabalho, lar e botequim. O cotidiano dos trabalhadores no Rio de Janeiro da belle époque. Campinas: Editora da UNICAMP, 2001.

${ }^{17}$ Ibidem, p. 41.

${ }^{18}$ FOUCAULT, Michel. Microfísica do poder. São Paulo: Graal, 2008.
} 
baixos índices de criminalidade, o que era particularmente notável no âmbito da população infantojuvenil.

Em 1974, o general-presidente da República, Ernesto Geisel, indicou Antônio Carlos Konder Reis, vinculado à Aliança Renovadora Nacional (Arena), partido político oficial do regime autoritário, para assumir, no ano seguinte, na condição de "biônico" ${ }_{19}^{19}$ o cargo de governador do estado de Santa Catarina. Foi neste contexto de alinhamento político-institucional do governo estadual e do governo federal que, em 1975, foi criada a mencionada Fucabem. ${ }^{20}$

A partir desta época, o governo de Santa Catarina passou a gerir diretamente, por meio de unidades de atendimento e recursos humanos, as políticas públicas voltadas à população infantojuvenil considerada infratora. No período, isso representou o rompimento com as ações de cunho assistencialista e religioso ${ }^{21}$ que vigiam desde a década de 1930 no estado, especialmente no Abrigo de Menores do Estado de Santa Catarina, localizado na cidade de Florianópolis.

A partir das constatações expostas pelo jurista Nuno Campos, ${ }^{22}$ que atuou como promotor de justiça na Vara de Menores da Comarca da capital no decorrer da década de 1970, é possível conhecer, em parte, o perfil dos adolescentes acusados da prática de infrações naquele período. Ao analisar os processos investigatórios existentes naquela instância judicial entre os anos de 1971 a 1976, Nuno Campos identificou que os "menores", em regra, eram do sexo masculino, se encontravam na faixa etária entre 16 e 17 anos e eram analfabetos ou não haviam concluído a quarta série do então primeiro grau de ensino. Apesar de as infrações, principalmente furtos simples, serem realizadas no centro da cidade de Florianópolis, os "menores" residiam nos subúrbios da capital ou nas cidades vizinhas. Ao abordar a tipificação das infrações, o promotor de justiça informou:

Verifica-se, no referente aos crimes contra o patrimônio, um grande percentual de furtos simples; um pouco menos da metade do total dos crimes contra o patrimônio. Isto indica que nosso

\footnotetext{
${ }^{19} \mathrm{O}$ termo 'biônico' foi utilizado durante a Ditadura Militar para se referir aos governantes que ocupavam cargos públicos a partir da indicação dos próceres do regime autoritário.

${ }^{20}$ SANTA CATARINA. Lei $n^{\circ}$ 5.089, de 14 de maio de 1975.

${ }^{21}$ SANTOS, Rita Brancato. $\mathrm{O}$ fogo da modernização: tradição e tecnicismo no Abrigo de Menores do Estado de Santa Catarina em Florianópolis (1940-1980). Dissertação (Mestrado em Sociologia Política), Universidade Federal de Santa Catarina, Florianópolis, 2006. Disponível em https://repositorio.ufsc.br/ handle/123456789/88603 Acesso em: fev/2021.

${ }^{22}$ CAMPOS, Nuno. 0 Estado e os Menores de Conduta Anti-social. Dissertação (Mestrado em Direito), Universidade Federal de Santa Catarina - Florianópolis, 1978.
} 
menor infrator comete furtos sozinho e de maneira primária. Os furtos qualificados o são pelo concurso de autores ou pelo arrombamento, principalmente de automóveis. Crimes contra o patrimônio com violência à pessoa quase não ocorrem.

Quanto aos crimes contra a vida verificamos, pelo levantamento efetuado, que a grande incidência, neste tipo, é de lesões corporais (brigas). O número de homicídios é muito pequeno. Nos seis anos pesquisados ocorreram somente 9 casos. $^{23}$

O perfil dos "menores" e a tipificação das condutas elaborada por Nuno Campos concorrem para evidenciar que a criação de instituições de cunho parapenal, como o Centro de Recepção e Triagem e o Centro Educacional para Menores, posteriormente chamado de São Lucas, em $1973^{24}$ - sendo esta a primeira unidade de internação exclusivamente destinada à contenção de "menores" considerados infratores -, não refletia o aumento da então chamada delinquência infantojuvenil em Santa Catarina. A criação de entidades que acolhiam os "menores" considerados infratores de todo o estado, como a da Fucabem, aponta no sentido das articulações entre os interesses políticos das elites regionais e nacionais no contexto da Ditadura Militar. ${ }^{25} \mathrm{~A}$ emergência de tais ações governamentais resultava da política de recrudescimento e criminalização da população infantojuvenil pobre, acentuada pelo contexto sociopolítico do regime. Os dados indicam que na década de 1970 o "problema do menor" em Santa Catarina se relacionava à pobreza muito mais do que a infrações. ${ }^{26}$

Durante seu período de funcionamento, a Fucabem (sempre consorciada à Funabem) atuou em duas frentes principais: o Programa de Prevenção à Marginalidade do Menor e o Programa Sócio-Terapêutico e de Apoio. Na primeira frente, empenhava-se em atender aos "menores" considerados carentes e em risco de se tornarem abandonados; de outra parte, visava a reparação das condutas compreendidas como antissociais. ${ }^{27}$ Para a consecução desses dois objetivos, a Fucabem dispunha de dois tipos de unidades de internação. Por meio de convênios estabelecidos com municípios e entidades assistenciais, as

\footnotetext{
${ }^{23}$ CAMPOS, op. cit. p. 57.

${ }^{24}$ SANTA CATARINA. Lei no 4744, de 30 de junho de 1972.

${ }^{25}$ AREND, Silvia Maria Fávero; DAMINELLI, Camila Serafim. Políticas sociais para infância e juventude carente e infratora (1970-1980). In: BRANCHER, Ana; LOHN, Reinaldo (org.). Histórias na Ditadura: Santa Catarina (1964-1985). Florianópolis: Editora UFSC, 2014. p. 181-205.

${ }^{26}$ Ibidem.

${ }^{27}$ FERNANDES, Angela. Repercussão do Código de Menores no Centro Educacional São Mateus. Monografia (Curso de Serviço Social), Universidade Federal de Santa Catarina - Florianópolis, 1990.
} 
unidades destinadas à internação de "menores" considerados abandonados se encontravam distribuídas em todas as regiões do estado. Entre 1974 e 1977, por meio do Programa de Prevenção à Marginalidade do Menor, o estado atendeu a aproximadamente 30 mil crianças e adolescentes. No mesmo período, o Programa Socioterapêutico e de Apoio foi responsável por aproximadamente 600 atendimentos de "adolescentes em conflito com a lei". ${ }^{28}$

Devido à baixa demanda em termos demográficos, as unidades destinadas à internação de "menores" considerados infratores limitavam-se a duas, que se localizavam na região de Florianópolis: os mencionados Centro Educacional para Menores e o Centro de Recepção e Triagem. Em 1984, o Tribunal de Justiça de Santa Catarina, fundamentando-se no Código de Menores de $1979,{ }^{29}$ com vistas a regular a institucionalização de "menores" nas unidades de internação geridas pelo estado ou por entidades conveniadas, emitiu o Provimento ${ }^{\circ}$ 20/1984..$^{30}$ A partir desta normativa, crianças ou adolescentes que se encontrassem na situação de privação ou de restrição à liberdade, foi classificada em duas categorias: "os menores em desvio de conduta e infratores, não notoriamente perigosos" e "os menores infratores notoriamente perigosos", de acordo com o Provimento ${ }^{\circ} 20$, de 11 de setembro de 1984:

Art. 15 - Os menores infratores notoriamente perigosos, na faixa etária de 14 a 18 anos, poderão ser internados no Centro Educacional São Lucas, localizado na Comarca de São José.

$\S$ Único - Considera-se infrator notoriamente perigoso, aquele cuja personalidade, antecedentes e condições, bem como os motivos e circunstâncias da ação, presumam a necessidade de tratamento em regime de contenção, com o propósito de se evitar a continuidade da prática de outras infrações graves. ${ }^{31}$

No decorrer das décadas de 1970 e 1980, de maneira geral, os governantes de Santa Catarina pareciam não encontrar grandes dificuldades para executar as "medidas de privação de liberdade" determinadas pelos juízes de menores que atuavam nas comarcas do estado. "Os adolescentes em conflito

\footnotetext{
${ }^{28}$ DUARTE, Sérgio Guerra. Menores, marginalidade e educação. Dissertação (Mestrado em Educação), Fundação Getúlio Vargas, Rio de Janeiro, 1978.

${ }^{29}$ BRASIL, Lei 6.667, de 10 de outubro de 1979.

${ }^{30}$ SANTA CATARINA. Provimento n²0, de 11 de setembro de 1984.

${ }^{31}$ Idem.
} 
com a lei" eram encarcerados junto com os adultos nas penitenciárias ou enviados para as duas citadas unidades. ${ }^{32}$

Apesar do escamoteamento pela censura e do uso do aparato estatal para disseminar propagandas enaltecendo o atendimento prestado pelas instituições de internação e abrigamento de menores, há relatos contundentes sobre violações de direitos humanos neste período. Em 02 março de 1985, portanto, dias antes dos militares entregarem o governo a um presidente civil, valendo-se do novo contexto político, o jornal o Estado ${ }^{33}$ publicou matéria informando sobre a prática de torturas em uma unidade destinada à internação de crianças abandonadas.

Além dos catigos físicos, consta que as crianças sofrem toda sorte de coação moral e psicologica. Elmar Forte Melo afirmou que é rotina também um tipo de castigo, pelo qual a criança fica trancada no banheiro desde as primeiras horas da manhã até o final da tarde, sem comer e beber nada.

De acordo com a publicação, os fatos ocorriam no Lar Menino Feliz, no município de Jaguaruna. Infere-se que no decorrer da Ditadura Militar, casos semelhantes aos relatados tenham se repetidos em outras unidades geridas pela Fucabem ou a ela conveniadas. Contudo, em decorrência da censura imposta pelo regime autoritário os fatos não se tornavam públicos. ${ }^{34}$

Ocorre que no ínterim transcorrido entre os anos finais da década de 1970 e meados da década de 1990 o cenário socioeconômico catarinense passou por significativas mudanças. Findado o período de acelerado crescimento econômico experimentado na primeira década da Ditadura Militar, no início da década de 1980 o país atravessou uma forte crise econômica. ${ }^{35} \mathrm{~A}$ reestruturação dos processos de produção impactou o tecido social do país, precarizando ainda mais as condições de vida da população pobre. Em Santa Catarina, neste mesmo período, ocorreu a inversão da distribuição demográfica da população entre o campo e a cidade. Com a crescente migração das populações rurais para as cidades, os problemas habitacionais e a ausência de serviços públicos adquiriram cada vez maior vulto.

\footnotetext{
${ }^{32}$ MACHIESKI, Elisangela da Silva. Crianças e adolescentes nas páginas do jornal: uma infância perigosa ou uma infância em perigo? (Criciúma, 1970 -1990). 2013. 169 f. Dissertação (Mestrado em História), Universidade do Estado de Santa Catarina, Florianópolis, 2013. Disponível em: http://www.faed.udesc.br/ arquivos/id_submenu/784/elisangela_da_silva_machieski.pdf Acesso em: fev/2021.

${ }^{33} \mathrm{Na}$ década de 1980, o jornal O Estado era o principal periódico catarinense.

${ }^{34}$ AREND; DAMINELLI, op. cit.

${ }^{35}$ BRESSER-PEREIRA, Luiz Carlos. A construção política do Brasil: sociedade, economia e estado desde a Independência. São Paulo: Editora 34, 2014.
} 
No decorrer da década 1990, várias regiões do estado passaram a registrar um aumento dos índices de violência urbana. Além dos mencionados movimentos migratórios de famílias para as cidades-polo de desenvolvimento econômico do estado - Joinville, Blumenau, Chapecó, Criciúma, Lages e Florianópolis -, que geravam grande exclusão social, outra questão pode ser mencionada para compreender a associação deste fenômeno ao universo infantojuvenil: o envolvimento de adolescentes (sobretudo do sexo masculino) em atividades consideradas ilegais, com destaque para o tráfico de drogas. ${ }^{36}$

Tendo em vista este cenário, houve um significativo aumento no número de denúncias de atos infracionais graves no estado de Santa Catarina. Este fato provocou um aumento do contingente de adolescentes em cumprimento de medidas socioeducativas de privação de liberdade. De acordo com o Relatório Anual de Atividades do Ministério Público de Santa Catarina de $1998,{ }^{37}$ no curso de um ano foram registradas 9.151 ocorrências de atos infracionais no estado. Deste total, 1.835 casos resultaram em representações junto ao Poder Judiciário. Ou seja, nesses casos, os representantes do MPSC reconheciam a existência e a autoria da prática de atos infracionais, peticionando junto à Vara da Infância e Juventude pelo prosseguimento do processo.

\section{"Descaminhos" de Pedro Henrique: municipalização das políticas públicas e o atendimento nas unidades de internação}

O Estatuto da Criança e do Adolescente buscou garantir aos "adolescentes em conflito com a lei” a instituição de um processo legal de acordo com todos os ritos indispensáveis ao Estado de Direito, bem como com a própria assistência judiciária. As sentenças dos magistrados, por sua vez, segundo a mencionada legislação, deviam buscar um "equilíbrio" entre o grau de responsabilização relativo ao ato infracional cometido e a medida socioeducativa aplicada $^{38}$ - advertência, prestação de serviços à comunidade, liberdade assistida, regime de semiliberdade ou internação em estabelecimento educacional -, procurando, se possível, evitar a "privação de liberdade". o Estado brasileiro tornou-se também o responsável pela garantia da integridade da

\footnotetext{
${ }^{36}$ MONTEIRO, Felipe Mattos. Uma tragédia anunciada: estudo da dinâmica das taxas de homicídios nos municípios de Santa Catarina no período de 1996 a 2008. Dissertação (Mestrado em Sociologia Política), Universidade Federal de Santa Catarina, Florianópolis, 2009. Disponível em: https://repositorio.ufsc.br/ xmlui/handle/123456789/93109 Acesso em: mar/2021.

${ }^{37}$ SANTA CATARINA. Relatório Anual de Atividades do Ministério Público. Florianópolis, 1998.

${ }^{38}$ Legalmente, as medidas socioeducativas consistem na responsabilização, por parte do Estado, dos adolescentes sentenciados por prática de ato infracional.
} 
vida das pessoas em situação de cumprimento de medidas socioeducativas, assim como por prover a subsistência, a saúde, a escolarização e a formação para o trabalho dos custodiados nas unidades de internação. ${ }^{39}$

No intuito de assegurar que crianças e adolescentes de fato pudessem acessar os direitos postulados na Constituição Federal de 1988, conforme prescrito no Artigo n. ${ }^{\circ} 86$ do Estatuto da Criança e do Adolescente, as políticas públicas seriam executadas "através de um conjunto articulado de ações governamentais e não-governamentais, da União, dos estados, do Distrito Federal e dos municípios".

Mesmo diante do aumento dos problemas sociais que afetavam a vida de crianças e adolescentes no período, tão logo o Estatuto da Criança e do Adolescente entrou em vigor, o governo catarinense, então, como referido, sob o comando de Vilson Kleinübing, do Partido da Frente Liberal (PFL), desconsiderando a necessidade do atendimento articulado entre as três esferas de governo, limitou-se a adotar o previsto no Artigo no 88 da mesma lei: a "municipalização do atendimento".

De imediato, valendo-se da hermenêutica mais adequada aos interesses do governo estadual, o executivo catarinense entendeu que deveria transferir totalmente para a competência dos municípios as atribuições que por anos vinham sendo compartilhadas entre os dois entes, seja pela execução direta da Fucabem ou pelo apoio técnico e o aporte financeiro repassado aos municípios. Com tal decisão, os governantes aderiam à política neoliberal de desresponsabilização do Estado pela execução das políticas sociais, projeto que avançava sobre o país naquele momento. ${ }^{40}$ Deixaram, assim, de executar os programas de prevenção à marginalização de crianças e adolescentes e se eximiram de quaisquer responsabilidades em relação à execução das medidas socioeducativas em meio aberto, isto é, com Liberdade Assistida (LA) e Prestação de Serviços à Comunidade (PSC).

Ao propor que a execução de medidas socioeducativas em meio aberto fosse municipalizada, o Estatuto da Criança e do Adolescente compreendia o município como locus privilegiado em serviços e equipamentos sociais, possibilitando, em virtude do caráter pedagógico da medida, a manutenção dos vínculos familiares e comunitários. ${ }^{41}$ Portanto, a partir da articulação dos

\footnotetext{
${ }^{39}$ BRASIL. Lei n. ${ }^{\circ} 8.069$, de 13 de julho de 1990. Artigos 3; 4; 6, 5; 100; 108; 110; 111; 112; 124 e125.

${ }^{40}$ ZAMORA, Maria Helena. Aos quinze: o Estatuto da Criança e do Adolescente em tempos neoliberais. In: SYDOW, Evanize; MENDONÇA, Maria Luisa (Orgs.). Direitos Humanos no Brasil 2005: Relatório da Rede Social de Justiça e Direitos Humanos em colaboração com Global Exchange. 2005. p. 201-206.

${ }^{41}$ BRASIL. Sistema Nacional de Atendimento Socioeducativo - SINASE/Secretaria Especial dos Direitos Humanos - Brasília: CONANDA, 2006. 100 p.
} 
entes federativos, com vistas a proporcionar à criança e ao adolescente pleno acesso a seus direitos sociais, a execução da medida se daria prioritariamente no espaço territorial do município. ${ }^{42}$ Destoando disso, na compreensão do executivo catarinense, a municipalização do atendimento socioeducativo significava limitar as responsabilidades do governo estadual à execução de medidas de privação e restrição de liberdade.

Em janeiro de 1991, atendendo às prescrições do Estatuto da Criança e do Adolescente, o governo do Estado criou o Conselho Estadual dos Direitos da Criança e do Adolescente (Cedca). Por conta de suas atribuições, o órgão foi designado a apoiar tecnicamente os conselhos municipais dos direitos da criança e do adolescente e os conselhos tutelares. Contudo, tais ações ocorreram sem a devida previsão de transferência de recursos para financiar a implantação dos programas de atendimento. No ano seguinte, consumada a extinção da Fucabem, a gestão dos dois centros de internação permanente e do centro de internação provisória foi repassada à Secretaria de Justiça e Administração (SJA). ${ }^{43}$

Deflagrado o processo de municipalização das medidas socioeducativas em meio aberto, os municípios catarinenses foram repentinamente sobrecarregados por meio do processo de criação de conselhos e instituição de programas. Tendo em vista a política até então executada pela Fucabem, boa parte das prefeituras e instituições locais não detinha infraestrutura e recursos humanos aptos a executar medidas socioeducativas em meio aberto. A nova configuração, portanto, manteve muitos "adolescentes em conflito com a lei" na condição de terem seus direitos negligenciados.

Foi neste contexto de inconsistências jurídicas sobre a aplicabilidade do Estatuto da Criança e do Adolescente que Pedro Henrique, mesmo não tendo cometido ato infracional mediante grave ameaça ou violência, foi sentenciado com medida socioeducativa de privação de liberdade em 1997. 0 adolescente era morador de Criciúma, então o quinto maior município do estado e o maior da região Sul de Santa Catarina. No entanto, apesar de a cidade ser sede de comarca, não havia unidade de atendimento socioeducativo na qual o adolescente pudesse cumprir a determinação judicial.

Ressalte-se que a medida socioeducativa de internação aplicada ao adolescente decorria da reincidência na prática de pequenos furtos. Dos autos depreende-se que ele não representava iminente ameaça à segurança daquela

\footnotetext{
${ }^{42}$ Idem.

${ }^{43}$ Decreto n 3.538, de 20 de abril de 1993.
} 
comunidade. Ainda assim, foi encaminhado para cumprir a internação no Centro Educacional São Lucas. Esta unidade se localizava na região da Grande Florianópolis, distante mais de 200 quilômetros da sua residência. O Centro Educacional São Lucas, cuja arquitetura prisional foi erguida sob as diretrizes da Fucabem, era a maior unidade de internação de adolescentes do estado de Santa Catarina. Ao longo da década de 1980 foi considerada uma unidade destinada a "menores infratores notoriamente perigosos", conforme se informou anteriormente. Mesmo considerando, em uma perspectiva legal, que a partir da vigência do Estatuto da Criança e do Adolescente as diretrizes jurídicas anteriores haviam sido revogadas, no plano das representações sociais seguiam pesando sobre os internos do Centro Educacional São Lucas os estigmas ${ }^{44}$ de serem considerados "menores" notoriamente perigosos.

Distinguindo-se das legislações "menoristas" do início do século XX, que possibilitavam que os "menores delinquentes" fossem encaminhados a patronatos agrícolas ${ }^{45}$ a milhares de quilômetros de suas cidades de origem, $\mathrm{o}$ Estatuto da Criança e do Adolescente previa para Pedro Henrique e os demais adolescentes custodiados pelo Estado o direito de permanecerem internados "na mesma localidade ou naquela mais próxima ao domicílio de seus pais ou responsável". ${ }^{46}$

No entanto, naquele momento, mesmo o Estado de Santa Catarina estando dividido em seis mesorregiões e 260 municípios, o executivo do estado catarinense havia restringido sua atuação direta a três unidades de atendimento socioeducativo de internação: o Centro Educacional Regional de Lages, localizado na região Serrana, e os referidos centros na Grande Florianópolis, o São Lucas e o Centro de Atendimento Provisório.

Buscando assegurar aos adolescentes acusados da prática de ato infracional a condição de sujeitos de direitos mesmo durante o período de cumprimento de medida socioeducativa de internação, o Estatuto da Criança e do Adolescente previu um rol de direitos específicos, uma vez que o objetivo da medida (socioeducativa) era "possibilitar a inclusão social de modo mais célere possível e, principalmente, o seu pleno desenvolvimento como pessoa". ${ }^{47}$

\footnotetext{
${ }^{44}$ GOFFMAN, Erving. Estigma: notas sobre a manipulação da identidade. Tradução: Marcia Bandeira de Mello leite Nunes. 4 ed. Rio de Janeiro: LTC, 2008.

${ }^{45}$ BRASIL. Decreto nํㅜㄴ.706, de 25 de julho de 1919.

${ }^{46}$ BRASIL. Lei nº 8.069, de 13 de julho de 1990. Art. 124, inciso VI.

${ }^{47}$ BRASIL. 2006, op. cit. p. 28.
} 
Contudo, para os adolescentes do estado, de acordo com os autos, observa-se que as medidas adotadas pelo governo de Santa Catarina inviabilizavam o exercício de tais direitos. Durante o período em que esteve internado no Centro Educacional São Lucas, contrariando a previsão legal de rigorosa separação por critérios de idade, compleição física e gravidade da infração, ${ }^{48}$ Pedro Henrique convivia interagindo com adolescentes cuja faixa etária variava entre 14 e 19 anos. No mesmo sentido, a separação pela gravidade dos atos infracionais não era respeitada. João Lucas, ${ }^{49} 17$ anos, que cumpria medida socioeducativa sob acusação da prática de atos infracionais análogos a homicídio e estupro, entre outros, informou ser amigo de Pedro Henrique, afirmando que durante o período de internação "conversavam muito".

Antes da internação, João Lucas também não residia na Região da Grande Florianópolis. Morador da Região Serrana, o adolescente também estava a mais de 200 quilômetros de seu município de origem. Tal situação se repetiu em relação aos outros cinco adolescentes ouvidos nos autos. Nenhum deles era residente na região de Florianópolis ou dela natural. No decorrer das oitivas, outros dois adolescentes informaram cumprir medida de internação em razão de condenação por prática de ato infracional análogo a furto. Ou seja, excetuada a hipótese de tais infrações terem sido praticadas de maneira reiterada, a princípio, a aplicação da medida socioeducativa de internação não seria a mais adequada.

Não há evidências de que Pedro Henrique, no decorrer do período em que esteve sob custódia do Estado, tenha recebido atendimento biopsicossocial compatível com suas peculiaridades de saúde, conforme o preconizado no Estatuto da Criança e do Adolescente. Além de fugir quatro vezes da unidade de internação, o adolescente não recebeu tratamento terapêutico para tratar da dependência química que o acometia desde os nove anos de idade, o que se somava, conforme os autos de sua sentença de internação, ao fato de ser "portador de epilepsia". Em contraposição à política estatal, considerando as questões de saúde e compreendendo que as infrações do adolescente não se enquadravam como graves, os próprios profissionais da equipe técnica da instituição entendiam que naquela unidade de internação o adolescente não recebia o atendimento adequado. Eis o que afirmaram os técnicos da instituição:

\footnotetext{
${ }^{48}$ BRASIL. 1990, op. cit. Art. 123.

${ }^{49}$ Nome fictício.
} 
Este centro de internação não possui características de programa para desintoxicação de dependentes químicos, e isto relatado ao juízo da comarca de origem do processo. Apesar de contarmos com precariedade do atendimento não qualificado para o caso em tela, todos os esforços profissionais estavam voltados para encontrar alternativas que oferecem ao adolescente outras condições de vida. ${ }^{50}$

Tendo em conta que o adolescente havia sido privado de liberdade com 12 anos de idade e que desde os 9 anos era dependente químico, possivelmente, mesmo antes da internação, os representantes do Estado haviam falhado em suas atribuições de garantir a Pedro Henrique proteção integral e prioridade no acesso às políticas públicas.

Conforme o Art. 125, do Estatuto da Criança e do Adolescente, "é dever do Estado zelar pela integridade física e mental dos internos, cabendo-lhe adotar as medidas adequadas de contenção e segurança". Neste sentido, é possível considerar que o atendimento ofertado a Pedro Henrique, e que contribuiu para a sua morte, ressalte-se, demonstra que as políticas públicas adotadas pelo governo de Santa Catarina para o atendimento da infância considerada infratora seguiam direção diversa daquela apontada pelas prescrições do Estatuto da Criança e do Adolescente.

Acentue-se que a singularidade da trajetória de Pedro Henrique limita-se ao evento trágico que encerrou sua vida. De resto, os demais traumas sociais, seja a condição de pobreza de seus pais, o uso de drogas, a prática de pequenos furtos, a institucionalização, o atendimento socioeducativo incompatível com a Doutrina da Proteção Integral ou as reiteradas violações de direitos, retratam uma realidade comum na trajetória de muitos adolescentes brasileiros. Dessa forma, no contexto das políticas públicas destinadas aos “adolescentes em conflito com a lei", em vida, Pedro Henrique se aproximou mais da regra que da exceção.

Possivelmente, em virtude das condições de pobreza e desconhecimento do Direito, a família de Pedro Henrique não adotou nenhuma medida buscando responsabilizações pelo falecimento do adolescente. Não consta dos autos que algum membro da família tenha sido chamado a se manifestar, seja pela Polícia Civil, pelo Ministério Público ou pelo Poder Judiciário.

Em setembro de 1998, portanto, três meses após o falecimento de Pedro Henrique, finalizado o transcurso do inquérito policial que apurou a morte

${ }^{50}$ Autos do Processo Penal número 0004164 [...] 1ํCartório Criminal da Comarca de São José (Santa Catarina). 
do adolescente, não sendo encontrados indícios de crime, o caso foi arquivado. No entanto, estando ciente do caso por meio de uma matéria jornalísti$\mathrm{ca}^{51}$ publicada pela imprensa local, o Centro de Direitos Humanos da Grande Florianópolis (CDHGF) protocolou um pedido de esclarecimentos junto ao MPSC. Diante desta solicitação, o MPSC peticionou pela reabertura do caso, o que foi acatado pelo Judiciário. Assim, o inquérito policial foi reaberto e outros documentos, inclusive um novo laudo pericial, foram arrolados nos autos.

$O$ inquérito policial novamente não apontou para a existência de indícios de crime. Assim, em novembro de 1999, o MPSC solicitou o arquivamento do processo. Todavia, compreendendo que ainda havia fatos a serem esclarecidos, o CDHGF peticionou pelo prosseguimento das investigações. Após novas investigações, em dezembro de 2000, convicto que a morte de Pedro Henrique não decorria de ato criminoso, outra vez o MPSC peticionou pelo arquivamento do caso, pedido que foi acatado pelo representante do Poder Judiciário.

Transcorrido uma década, em junho de 2011, após decretada a interdição judicial do Centro Educacional São Lucas, em decorrência da constatação da imputação de graves violações de direitos humanos aos adolescentes ali institucionalizados, mais uma vez o CDHGF peticionou pelo desarquivamento do processo de Pedro Henrique. A solicitação de desarquivamento foi acatada pelo MPSC. Após reexaminar o caso, em agosto de 2014, mais uma vez o MPSC decidiu pela manutenção do arquivamento.

Além do arquivamento do processo penal, não consta responsabilização judicial no âmbito cível.$^{52}$ Assim, não fosse a publicação de uma matéria jornalística e as iniciativas do CDHGF, possivelmente as ações dos gestores do estado de Santa Catarina que culminaram na morte de Pedro Henrique seriam relegadas a completo esquecimento.

\section{Buscando novo rumo para as políticas públicas: atuação do Ministério Pública de Santa Catarina}

Da mesma forma que os autos referentes ao caso de Pedro Henrique, o Inquérito Civil Público (ICP) 001/95 instaurado pelo MPSC por meio da Portaria

\footnotetext{
${ }^{51}$ Encontra-se anexada aos autos uma página do jornal Diário Catarinense, de 18 de junho de 1998, na qual consta uma matéria jornalística sobre a morte de Pedro Henrique ocorrida no Centro Educacional São Lucas. 0 título da reportagem era o seguinte: "Desentendimento em jogo acaba em morte". 0 referido periódico era o principal jornal em circulação no estado de Santa Catarina no período.

${ }^{52} \mathrm{Em}$ pesquisas realizadas no sistema de protocolo do TJSC, não foi identificado nenhum processo em que os pais do adolescente tenham solicitado indenização pela morte de Pedro Henrique.
} 
$\mathrm{n}^{\mathrm{o}}$ 809, de 02 de agosto de 1995, contribui para informar sobre as formas de aplicabilidade do Estatuto da Criança e do Adolescente em relação aos adolescentes catarinenses considerados autores de atos infracionais no decorrer da década de 1990. A instauração do referido procedimento judicial adveio do entendimento manifestado pelo Centro das Promotorias da Infância do MPSC de que em Santa Catarina, tanto em âmbito estadual quanto municipal, os gestores públicos não estavam implantando as políticas públicas destinadas a assegurar à criança e ao adolescente a proteção integral e a prioridade no atendimento público.

O objetivo do inquérito, portanto, era apurar as responsabilidades do governo estadual e dos governos municipais em relação à consecução/aplicação de políticas de atendimento à criança e ao adolescente. A partir da instauração do ICP 001/95, o Cedca, na condição órgão de defesa e promoção dos direitos da criança e do adolescente, foi instado a informar ao MPSC quais medidas havia adotado para efetivar o prescrito no Art. nº 88 do Estatuto da Criança e do Adolescente. Nesse âmbito, entre outros pontos, a legislação aborda a questão da municipalização do atendimento, prevendo a criação de conselhos de direitos, de programas de atendimento e de fundos responsáveis pelo financiamento da política pública.

O Cedca, portanto, deveria informar ao MPSC as políticas deliberadas pelo órgão, inclusive os totais de recursos financeiros destinados à consecução dos programas de atendimento entre os anos de 1994 e 1995. Cabia-lhe, ainda, informar o orçamento previsto para o exercício de 1996. Da mesma forma, as prefeituras e os conselhos municipais dos direitos da criança e do adolescente deveriam informar sobre as medidas adotadas pelos municípios na promoção dos direitos da criança e do adolescente..$^{53}$

Após transitar por um ano e meio, em janeiro de 1997, o Centro das Promotorias da Infância do MPSC apresentou o Relatório de Conclusão do ICP 01/1995. Das conclusões extrai-se que, quando da instauração do citado inquérito, mesmo passados sete anos desde a promulgação do Estatuto da Criança e do Adolescente, $38 \%$ dos então cerca de 260 municípios existentes no estado ainda não haviam constituído sequer seus respectivos conselhos de direitos da criança e do adolescente. Em relação à instalação dos conselhos tutelares, a situação era ainda mais grave. 0 órgão público "encarregado pela

\footnotetext{
${ }^{53}$ SANTOS, Sidney Francisco Reis Dos. A justiça da infância e da juventude frente aos dilemas da cidadania: uma percepção sociológica a partir de algumas organizações da sociedade civil de Florianópolis. Dissertação (Mestrado em Sociologia Política), Universidade Federal de Santa Catarina, Florianópolis, 1997. Disponível em: https://repositorio.ufsc.br/xmlui/handle/123456789/77007 Acesso em: mar/2021.
} 
sociedade de zelar pelo cumprimento dos direitos da criança e do adolescente ${ }^{54}$ seguia inexistindo em $61 \%$ dos municípios catarinenses. Em alguns deles, como era o caso de Florianópolis, apesar da existência de ambos os conselhos, as condições de atendimento eram precárias devido às limitações financeiras.

Em virtude do averiguado no referido ICP, o governo de Santa Catarina foi compelido a ajustar sua política de atendimento à criança e ao adolescente às diretrizes da Doutrina da Proteção Integral. Agindo neste sentido, em julho de 1998, por meio da Secretaria de Estado da Justiça e Cidadania (SJC), pasta responsável pelo Sistema de Atendimento ao Adolescente Infrator, o executivo catarinense firmou junto ao MPSC um Termo de Compromisso de Ajustamento de Conduta (TAC). Conforme o pactuado entre o MPSC e a SJC, o objeto do referido instrumento era "dar cumprimento ao preconizado no Estatuto da Criança e do Adolescente no que se refere à Política de Atendimento dos direitos ali assegurados, e implantar o Plano Estadual de Promoção e Defesa dos Direitos da Criança, e do Adolescente". ${ }^{55}$

Buscava-se, assim, reverter, ao menos parcialmente, o desmonte das políticas públicas de atendimento à infância, reestruturando um sistema estatal capaz de assegurar os direitos preconizados no Estatuto da Criança e do Adolescente, sobretudo em relação aos programas de atendimento destinados aos adolescentes acusados da prática de atos infracionais. O TAC detalhou em 13 itens os compromissos assumidos pelo governo de Santa Catarina no sentido de ampliar e melhorar o Sistema de Atendimento ao Adolescente Infrator, prevendo, inclusive, o financiamento conjunto, previsto nos programas executados pelos municípios ou por organizações não governamentais.

Ao firmar o TAC, o executivo catarinense reconhecia, ao menos tacitamente, sua inépcia na condução dessa política pública, razão por que se comprometeu a criar ou a financiar o funcionamento de unidades de atendimento socioeducativo de internação provisória e semi-internação em todas as regiões do estado. Foi ainda instado a implantar mais duas unidades de atendimento socioeducativo de internação permanente - os chamados centros educacionais - e a manter um programa permanente de capacitação de profissionais para atuar nos programas socioeducativos.

a) Apoiar técnica e financeiramente o funcionamento dos programas municipais e de ONG'S destinados ao atendimento de adolescentes autores de ato infracional [...]

\footnotetext{
${ }^{54}$ BRASIL. 1990, op. cit. Art. 131.

${ }^{55}$ SANTA CATARINA. Termo de Compromisso de Ajustamento de Conduta, de 9 de junho de 1998.
} 
[...] c) Apoiar técnica e financeiramente, através de repasses mensais, todos os municípios que ajustaram com o Ministério Público a implantação dos Programas de Liberdade Assistida e Prestação de Serviços à Comunidade no Estado [...]

d) Manter financeiramente ou continuar mantendo os programas de Internação Provisória existentes nos municípios de São José, Lages, Joaçaba, Xanxerê, Chapecó, Caçador, Blumenau, Itajaí, Criciúma e Tubarão, a partir de 01/06/9 [...]

[...] f) Implantar Centros de Internação Provisória para atendimento regionalizado em São Miguel do Oeste, Concórdia, Mafra, Joinville, Balneário Camboriú, Tubarão, Rio do Sul e Criciúma, mantendo-os financeiramente a partir de 31/12/98, no máximo;

g) Prestar. apoio técnico e financeiro aos programas de semiliberdade implantados em Tubarão, Caçador e Blumenau a partir de $1 \% / 08 / 98$, no máximo;

h) Criar, implantar e manter programas de semiliberdade, até 01/02/99, em Florianópolis, Lages, Chapecó, São Miguel do Oeste, Concórdia, Mafra, Joinville, Balneário Camboriú, Criciúma, Itajaí, São José e Joaçaba; [...]

[...]j) Criar e implantar 2 (dois) Centros Regionais de Internamento - um em Joinville e outro em Criciúma, para atendimento de 20 a 30 adolescentes em cada um deles, no prazo máximo de 18 (dezoito) meses, a contar de 28.02.98. [...] $]^{56}$

A quantidade e a diversidade de medidas que, por meio do TAC, o governo de Santa Catarina se comprometia a adotar, informam sobre sua desresponsabilização anterior, a qual resultara na negligência estatal quanto à aplicação do Estatuto da Criança e do Adolescente, sobretudo em relação à infância acusada da prática de atos infracionais. Pedro Henrique poderia estar dentre os adolescentes eventualmente beneficiados pelo pactuado no TAC. Constava dos compromissos assumidos pelo governo, no prazo máximo de 18 meses, a construção de uma unidade de internação em Criciúma. No entanto, em trágica coincidência, o TAC só foi firmado em 9 de junho de 1998, sete dias antes da morte de Pedro Henrique.

Em que pese a legítima atuação do MPSC na defesa dos direitos das crianças e dos adolescentes, exigindo do executivo estadual providências em relação ao Sistema de Atendimento ao Adolescente infrator, cabe ressaltar a ciência e a participação do órgão em relação aos processos que culminaram

${ }^{56} \mathrm{Idem}$. 
na internação de Pedro Henrique e de seus pares. Da mesma forma, a partir dos autos, infere-se sobre a ciência em relação às condições da execução das medidas socioeducativas.

Assim, apesar da importância do ICP 01/1995 e do TAC firmado junto ao governo do estado de Santa Catarina, observam-se, como no verificado nas demais instituições, as permanências do discurso "menorista" no âmbito dos representantes do Ministério Público. Apesar do pactuado junto a este órgão, principalmente em relação à criação de programas de semiliberdade e instalação de novas unidades de atendimento socioeducativo para a internação provisória e a internação permanente, poucas cláusulas do TAC se constituíram em ações. Cabe sublinhar o que afirma Michel Foucault sobre a aplicabilidade da lei:

[...] seria hipocrisia ou ingenuidade acreditar que a lei é feita para todo mundo em nome de todo mundo; que é mais prudente reconhecer que ela é feita para alguns e se aplica a outros; que em princípio ela obriga a todos os cidadãos, mas se dirige principalmente às classes mais numerosas e menos esclarecidas; que, ao contrário do que acontece com as leis políticas ou civis, sua aplicação não se refere a todos da mesma forma[... $]^{57}$

A aplicabilidade do prescrito no Estatuto da Criança e do Adolescente, cuja execução demanda investimentos públicos, seguiu, em parte, sendo postergada. Os 18 meses previstos no TAC para a construção das unidades de atendimento socioeducativo de internação para os "adolescentes em conflito com a lei" das cidades de Joinville e de Criciúma foram protelados e essas instituições só se tornaram realidade cerca de duas décadas mais tarde.

\section{Considerações finais}

No decorrer da década de 1990, além da extinção da Fucabem, os governantes do executivo catarinense adotaram uma série de medidas jurídicas e político-administrativas com vistas a adequar as políticas públicas para os "adolescentes em conflito com a lei" às prescrições do Estatuto da Criança e do Adolescente. No entanto, os resultados das medidas governamentais, ao invés de aproximar o sistema estadual das diretrizes de atendimento do garantismo integral, ${ }^{58}$ proposto pelo Estatuto da Criança e do Adolescente,

${ }^{57}$ FOUCAULT, 2009, op. cit. p. 261.

${ }^{58}$ MARCÓN, Orvaldo Agustín. La responsabilidad del niño que delinque. Revista Katálysis, Florianópolis, v. 11, n. 2, p. 237 - 247, jul./dez. 2008. 
tomaram outras direções. Diante da condução dada pelos governantes do estado de Santa Catarina a essas políticas públicas, considera-se que a trajetória de Pedro Henrique, assim como a de outros adolescentes citados no texto, não foi fortuita no que diz respeito à violação de seus direitos. Tratou-se de uma reiterada tragédia social vivida por boa parte da população de crianças e adolescentes pobres em um país em que o exercício de direitos fundamentais continua sendo em larga medida constantemente solapado.

\section{Referências}

AREND, Silvia Maria Fávero. Direitos Humanos e Infância: construindo a Convenção sobre os Direitos da Criança (1978-1989), Tempo [online]. 2020, v. 26, n. 3. p. 605-623. Disponível em: https://doi.org/10.1590/TEM-1980-542X2020v260305 Acesso em: jul/2021.

AREND, Silvia Maria Fávero; DAMINELLI, Camila Serafim. Políticas sociais para infância e juventude carente e infratora (1970-1980). In: BRANCHER, Ana; LOHN, Reinaldo (org.). Histórias na Ditadura: Santa Catarina (1964-1985). Florianópolis: Editora UFSC, 2014. p. 181-205.

BOURDIEU, Pierre. A ilusão bibliográfica. In: FERREIRA, Marieta de Moraes; AMADO, Janaina (org.). Usos e abusos da História Oral. Rio de Janeiro: Editora da FGV, 1996. p. 183-191.

BRESSER-PEREIRA, Luiz Carlos. A construção política do Brasil: sociedade, economia e estado desde a Independência. São Paulo: Editora 34, 2014.

CAMPOS, Nuno. O Estado e os Menores de Conduta Anti-social. Dissertação (Mestrado em Direito), Universidade Federal de Santa Catarina, Florianópolis, 1978.

CANTISANO, Pedro; DIAS PAES, Mariana Armond. Apresentação: Processos judiciais e escrita da história na América Latina. Varia História [online]. 2021, v. 37, n. 74, p. 353-360. Disponível em: https://doi.org/10.1590/0104-87752021000200002 Acesso: jul/2021.

CHALHOUB, Sidney. Trabalho, lar e botequim. O cotidiano dos trabalhadores no Rio de Janeiro da belle époque. Campinas: Editora da UNICAMP, 2001.

DAMINELLI, Camila Serafim. Governar, assistir, tolerar: uma história sobre infância e juventude em Florianópolis através das páginas de O Estado (19791990). 2013. Dissertação (Mestrado em História), Universidade Federal de 
Santa Catarina, 2013. Disponível em: https://repositorio.ufsc.br/bitstream/ handle/123456789/107139/317827.pdf>. Acesso em: fev/2021.

DUARTE, Sérgio Guerra. Menores, marginalidade e educação. Dissertação (Mestrado em Educação), Fundação Getúlio Vargas, Rio de Janeiro, 1978.

FERNANDES, Angela. Repercussão do Código de Menores no Centro

Educacional São Mateus. Monografia (Curso de Serviço Social), Universidade Federal de Santa Catarina, Florianópolis, 1990.

FOUCAULT, Michel. Microfísica do poder. São Paulo: Graal, 2008.

FOUCAULT, Michel. Segurança, território e população. São Paulo: Martins Fontes, 2008.

GOFFMAN, Erving. Estigma: notas sobre a manipulação da identidade. Tradução: Marcia Bandeira de Mello leite Nunes. 4 ed. Rio de Janeiro: LTC, 2008.

GONÇALVES, Hebe Signorini. Medidas socioeducativas: avanços e retrocessos no trato do adolescente autor de ato infracional. In: ZAMORA, Maria Helena (org.). Para além das grades: elementos para a transformação do sistema socioeducativo. Rio de Janeiro: PUC-Rio; São Paulo: Loyola, 2005. p. 35-61.

CHALHOUB, Sidney. Trabalho, lar e botequim. O cotidiano dos trabalhadores no Rio de Janeiro da belle époque. Campinas: Editora da UNICAMP, 2001.

MACHIESKI, Elisangela da Silva. Crianças e adolescentes nas páginas do jornal: uma infância perigosa ou uma infância em perigo? (Criciúma, 1970 -1990). 2013. Dissertação (Mestrado em História), Universidade do Estado de Santa Catarina, Florianópolis, 2013. Disponível em: http://www.faed.udesc.br/arquivos/id_ submenu/784/elisangela_da_silva_machieski.pdf Acesso em: fev/2021.

MARCÓN, Orvaldo Agustín. La responsabilidad del niño que delinque. Revista Katálysis, Florianópolis, v. 11, n. 2, p. 237 - 247, jul./dez. 2008.

MONTEIRO, Felipe Mattos. Uma tragédia anunciada: estudo da dinâmica das taxas de homicídios nos municípios de Santa Catarina no período de 1996 a 2008. Dissertação (Mestrado em Sociologia Política), Universidade Federal de Santa Catarina, Florianópolis, 2009. Disponível em: https://repositorio.ufsc.br/xmlui/ handle/123456789/93109 Acesso em: mar/2021.

MOSCOVICI, Serge. Representações sociais: investigações em psicologia social. Petrópolis, RJ: Vozes, 2007. 
SANTOS, Rita Brancato. o fogo da modernização: tradição e tecnicismo no Abrigo de Menores do Estado de Santa Catarina em Florianópolis (1940-1980). Dissertação (Mestrado em Sociologia Política), Universidade Federal de Santa Catarina, Florianópolis, 2006. Disponível em: https://repositorio.ufsc.br/ handle/123456789/88603 Acesso em: fev/2021.

SANTOS, Sidney Francisco Reis Dos. A justiça da infância e da juventude frente aos dilemas da cidadania: uma percepção sociológica a partir de algumas organizações da sociedade civil de Florianópolis. Dissertação (Mestrado em Sociologia Política), Universidade Federal de Santa Catarina, Florianópolis, 1997. Disponível em: https://repositorio.ufsc.br/xmlui/handle/123456789/77007 Acesso em: $\operatorname{mar} / 2021$.

SILVA, Roberto da. A construção do direito à convivência familiar e comunitária no Brasil. In: SILVA, Enid Rocha Andrade da. (coord.). 0 direito à convivência familiar e comunitária: os abrigos para crianças e adolescentes no Brasil. Brasília: IPEA/CONANDA, 2004. p. 287-301.

VERONESE, Josiane Rose Petry. Os direitos da criança e do adolescente. São Paulo. LTr, 1999.

ZAMORA, Maria Helena. Aos quinze: o Estatuto da Criança e do Adolescente em tempos neoliberais. In: SYDOW, Evanize; MENDONÇA, Maria Luisa (Orgs.). Direitos Humanos no Brasil 2005: relatório da Rede Social de Justiça e Direitos Humanos em colaboração com Global Exchange. 2005. p. 201-206.

\section{Fontes}

SANTA CATARINA. Lei no 4744, de 30 de junho de 1972.

SANTA CATARINA, Lei nº 5.089, de 14 de maio de 1975.

BRASIL. Decreto nº 13.706, de 25 de julho de 1919

BRASIL, Lei 6.667, de 10 de outubro de 1979.

BRASIL. Lei nº 8.069, de 13 de julho de 1990.

BRASIL. Sistema Nacional de Atendimento Socioeducativo - SINASE/Secretaria Especial dos Direitos Humanos - Brasília: CONANDA, 2006. 100 p.

SANTA CATARINA. Relatório Anual de Atividades do Ministério Público. Florianópolis, 1998. 
SANTA CATARINA. Decreto nํ⒊538, de 20 de abril de 1993.

SANTA CATARINA. Termo de Compromisso de Ajustamento de Conduta, de 9 de junho de 1998.

SANTA CATARINA. Autos do Processo Penal número 0004164 [...] 1ํo Cartório Criminal da Comarca de São José.

Artigo recebido para publicação em 05/04/2021 Artigo aprovado para publicação em 06/07/2021 